\title{
Get Protected! Recommendations for Staff in IR
}

\author{
Gabriel Bartal ${ }^{1}$ (D) $\cdot$ Eliseo Vano $^{2} \cdot$ Graciano Paulo $^{3}$
}

Received: 10 September 2020/ Accepted: 18 March 2021/Published online: 9 April 2021

(C) Springer Science+Business Media, LLC, part of Springer Nature and the Cardiovascular and Interventional Radiological Society of Europe (CIRSE) 2021

\begin{abstract}
Purpose Evaluation and registration of patient and staff doses are mandatory under the current European legislation, and the occupational dose limits recommended by the ICRP have been adopted by most of the countries in the world.

Methods Relevant documents and guidelines published by international organisations and interventional radiology societies are referred. Any potential reduction of patient and staff doses should be compatible with the clinical outcomes of the procedures.

Results The review summarises the most common protective measures and the needed quality control for them, the criteria to select the appropriate protection devices, and how to avoid unnecessary occupational radiation exposures. Moreover, the current and future advancements in personnel radiation protection using medical simulation with virtual and augmented reality, robotics, and artificial intelligence (AI) are commented. A section on the personnel radiation protection in the era of COVID-19 is
\end{abstract}

Gabriel Bartal

gbartal@gmail.com

Eliseo Vano

eliseov@med.ucm.es

Graciano Paulo

graciano@estescoimbra.pt

1 Tel Aviv, Israel

2 Radiology Department, Complutense University, Madrid, Spain

3 Medical Imaging and Radiotherapy Department, ESTESC Coimbra Health School, Instituto Politécnico de Coimbra, Coimbra, Portugal introduced, showing the expanding role of the interventional radiology during the pandemic.

Conclusion The review is completed with a summary of the main factors to be considered in the selection of the appropriate radiation protection tools and practical advices to improve the protection of the staff.

Keywords Occupational radiation protection . Musculoskeletal symptoms in interventional radiologist - Lead aprons · Protective goggles . Shielding

\section{Introduction}

Radiation protection (RP) during fluoroscopically guided procedures (FGP) is one of the most relevant issues in medical exposures. Radiation doses for patients and staff in FGP are considered the highest in medical imaging.

Occupational dose limits are applied to the staff, and the dose is measured by using personal dosimeters using the quantity "personal dose equivalent" Hp (10) [1]. Evaluation and registration of patient and staff doses are mandatory under the European Directive 2013/59/Euratom BSSD (Basic Safety Standards Directive) laying down basic safety standards for protection against the dangers arising from exposure to ionising radiation, published in 2014 [2].

The occupational dose limits recommended by the International Commission on Radiological Protection (ICRP) have been adopted by most of the countries in the world and by the BSSD [2], including the new occupational 
dose limit for the lens of the eyes: $20 \mathrm{mSv} / y e a r$, averaged over defined periods of 5 years, with no single year exceeding $50 \mathrm{mSv}$ [3].

The North American Society of Interventional Radiology (SIR) and the Cardiovascular and Interventional Radiology Society of Europe (CIRSE) have published joint guidelines on "Occupational radiation protection in Interventional Radiology " $[4,5]$, highlighting the need for appropriate education and training of the staff involved in the FGP and the availability of appropriate protection tools and equipment. CIRSE and SIR have also published a joint document on "Occupational radiation protection of pregnant or potentially pregnant workers in Interventional Radiology" [6].

Also, the ICRP has recently published a dedicated report on "Occupational Radiological Protection in Interventional Procedures" [7].

Interventionists should be well acquainted with the patient and staff RP rules. Patient and staff doses should be part of the global optimisation process in IR [7-9].

\section{Protective Devices and Quality Control}

Scatter radiation from the patient is the greatest source of exposure to the operator and other staff involved in FGP, and the RP tools should be used to protect them from this scattered radiation, while the most effective tool is the shielding [6].

There are two types of shielding:

1. Architectural,

a. included during the design of the interventional laboratories

2. Equipment-mounted shields,

a. Ceiling-suspended screens and curtains attached to the patient table that protect the main operator and other staff from the scatter radiation.

i. Ceiling-suspended transparent screens are usually $0.5-\mathrm{mm}$ lead equivalent and should be maintained between the irradiated volume and the operator $[7,8]$.

Properly placed shields have been shown to dramatically reduce operator dose, including eyes. Lens injuries have been reported in both operators and staff when systems which lack ceiling-suspended shields are used for complex interventional procedures.

\section{Lead Aprons and Lighter-Weight Aprons}

Personal protective devices comprise:

1. Aprons, vest/skirt configuration is preferred by many operators to reduce the risk of musculoskeletal/back injury.

2. Thyroid shields.

3. Eyewear.

4. Sterile radiation protection gloves.

The equivalent protection in thickness of lead is not always well specified, especially for the lead-free aprons. The attenuation of the aprons depends on the quality of the scatter radiation (and mean energy of the photons) which depends on the $\mathrm{kV}$ and filtration of the X-ray beam. The high filtration $\mathrm{X}$-ray beams used to reduce patient doses produce scatter radiation with higher photon energies. The same apron may be less effective in attenuation for this high energy scatter radiation.

The SIR-CIRSE guidelines suggest the wrap-around style with $0.25-\mathrm{mm}$ lead equivalent. When worn, the double thickness anteriorly should provide $0.5-\mathrm{mm}$ lead equivalence.

Of note is that the transmission of $70-100 \mathrm{kVp} \mathrm{X}$-rays through $0.5-\mathrm{mm}$ lead is approximately $0.5-5 \%$.

Whether the apron contains lead or other material is not the main issue since what matters is its protection of effectiveness. Similar levels of attenuation can be achieved because the alternative metals are more efficient per unit mass than lead for absorbing X-ray photons with energies between 40 and $88 \mathrm{keV}$. These aprons may be more effective for attenuating scatter radiation from tube voltages of $70-80 \mathrm{kV}$, but less effective for tube voltages above $100 \mathrm{kV}[10,11]$

Use of a lead apron and thyroid shield in FGP is inherent [4]. The vest/skirt configuration is preferred as they reduce the risk of musculoskeletal/back injury [11].

Moreover, the lead is a contaminant material for the environment. When these aprons deteriorate, their disposal must be carried out in a controlled manner to avoid contamination of the environment [8]. The design with a double layer zone at the front of the apron where the 2 layers overlap needs to consider that the lateral part of the left breast often is not completely covered by the overlap zone. One of the problems is that the protective aprons are often tailored to fit both male and female without considering differences between male and female body shape [8]. The aprons should be individually tailored. If oversized with widely open neck plunging necklines and openings under the arms, provide insufficient protection as critical organs like the lungs and oesophagus are exposed. The use 
of sleeves that cover the shoulders thus protecting the lungs could be considered.

Too short aprons can leave the upper legs and thighs inclusive part of the red bone marrow exposed. Protective aprons should be stored on hangers and never be folded, as cracks in the protective lining can appear, decreasing their protective effectiveness. Acceptability criteria should be established and applied in the facility [7].

Eyewear also requires specific selection criteria and better use wrap-around glasses/goggles. When protective eyewear is worn, eye exposure can still result from radiation scattered from the surrounding tissues of the interventionalist [7].

Protective gloves block $30-40 \%$ of the scattered radiation with some limitation of fingers movement and manipulating the catheters. When the interventionists have to operate closed to the irradiated area (i.e. biliary interventions), the use of protection gloves may be justified.

Disposable, sterile shielding pads are placed on the patient access point after it has been prepared and draped [4]. In case if it remains outside the field of radiation, the dose to the patient can increase without scatter reduction due to pad. Depending on tube operation, the scatter may even increase [12, 13].

The ICRP recommends that all staff in the room should wear protective aprons; the interventionalist should be protected by ceiling-suspended screens, table-suspended curtains, and shielding drapes when feasible. Other staff, such as radiographers, nurses, and anaesthesiology personnel, who need to remain near the patient, can benefit from protection by movable screens; other personnel can also benefit from protection by distance in addition to the protective apron [7].

A periodic quality control (QC) of the protection tools (including the curtains mounted on the patient table) should be established.

All lead protective aprons should be tested for shielding integrity on receipt and thereafter in regular intervals. Each apron should be given an individual identification number, which should not be removed. Testing is performed using fluoroscopy on a floating top table, and it will show faults, holes, and apron deterioration. If there is any doubt about an apron, it should be withdrawn from use until further advice is obtained [14, 15]. It is convenient to have a registry of the QC results and a mark on the protection tool after the control.

Radioprotective caps are marketed as devices that allegedly reduce operator's brain exposure [16]. In fact, the dose reduction to the brain obtained through routine use of the protective cap is insignificant due to the geometry of the scatter. The efficacy of lightweight radiation-protective hats when used in conjunction with a ceiling-mounted shield is negligible. [17]
The SIR-CIRSE guidelines also refer the ergonomic hazards of personal protective devices (particularly lead aprons) [4]. The so called "weightless apron" (or "zero gravity" tools) involved a rolling device from which the apron is hung, to be positioned behind the operator. These devices improve the ergonomics and safety and could be considered in some specific cases [10]. The different protection tools and their effectiveness should be evaluated by the staff in each IR unit with a cooperative work between the interventionists, the radiographers, nurses, and the medical physicist (Table 1). It may be a critical issue in decision-making process if rolling shields, the number of aprons, protective goggles, etc., are necessary. [7, 15].

\section{How to Select Personalised Protection Devices}

The best validation of the effectiveness of a protective tool is based on a careful follow-up after doses registered by the personal dosimeters. If two personal dosimeters are used (one over the apron and another under the apron, as recommended by ICRP), the measured doses may help to optimise the occupational radiological protection including the organs which are not protected by the apron $[7,8]$.

These are some key aspects to consider: Require the equivalent protection in thickness of lead (not always well specified), especially for the lead-free aprons. The same apron may be less effective in attenuation for this high energy scatter radiation.

- The weight of the apron is a critical aspect, but not always it is easy to have clear criteria due to that the weight depends not only on the lead equivalent thickness but also on the apron size and model. It should be included in the technical specifications.

- The advice of a medical physics expert (MPE) or a radiation protection expert (RPE) is recommended.

- Aprons: The cleaning aspects, disinfection, and period of guarantee should be considered.

Table 1 Lead equivalency of available personal protective devices

\begin{tabular}{ll}
\hline Protective tool & Lead equivalent $(\mathrm{mm})$ \\
\hline Aprons & $0.25-0.50$ \\
Ceiling-suspended screen & $0.5-1.0$ \\
Curtains & $0.5-1.0$ \\
Rolling shields & $0.5-1.0$ \\
Goggles & $0.25-0.75$ \\
Protective gloves & $0.03-0.10$ \\
RadPad Disposable shields & 0.125 \\
\hline
\end{tabular}


- Eyewear not always may be necessary, depending on the proper use of the ceiling-suspended screen and the workload.

- The different protection tools and their effectiveness should be evaluated with a cooperative work between the interventionists, radiographers, nurses and MPE. This may be a critical issue to decide whether several rolling shields, the number of aprons, goggles, etc., are necessary. [15]

\section{Personnel Radiation Protection in the Era of COVID-19}

The COVID-19 pandemic has significantly changed the way we practice interventional radiology. Recently, CIRSE and the Asia Pacific Society of Cardiovascular and Interventional Radiology (APSCVIR) published a checklist for preparing IR service for COVID-19 with clearly defined recommendations of using designated "hot" operating room with a mobile C-arm. Predesignated IR suite with high end angiographic imaging is required for urgent complex interventions.

Segregation of staff into smaller functional teams can prevent the entire service from being neutralised due to quarantine [16]. It is advisable for staff to stay inside the angio suite protected by mobile lead shields as the positive pressure doors must be closed during the entire procedure [17].

COVID-19 pandemic will not fade away in the near future, and knowing that the number of percutaneous interventions is likely to rise IR has taken a more prominent role accounting for an increased share of procedural volumes [18]. IR's will need to adapt to meet the challenges of a dynamic and uncertain future and demonstrate new core value of resilience [19].

New technology does not always carry the guarantee of lower radiation risks. For instance, the hybrid suites where extremely complex procedures take place are the new challenge. This is where there are a lot of people present standing on three sides of the table and even if you have the best protection, it will only work for one or maybe two persons, but not for the others.

\section{Main Factors to be Considered in the Selection of the Appropriate Means for RP}

1. Estimation of the real occupational risk (evaluating the different imaging and clinical protocols) to avoid unnecessary over-protection. The best for the estimation is a good personal monitoring programme with analysis of the results [20].

2. Management of the obese patients is challenging beyond increased scatter radiation as the IR suits were not designed to accommodate them [21]. Estimation/ simulation of the occupational doses can allow to choose the best protection strategies and, if necessary, distribution of the work, especially complex procedures between the available staff [22].

3. Organise training sessions for a good occupational protection using simulators for the analysis of occupational doses of the staff and suggest optimisation actions [23].

4. Electronic dosimeters could be used for preliminary tests [20]. Consider, if appropriate, their use with the management software to optimise the occupational radiation protection $[24,25]$.

\section{Future Developments in Radiation Protection in IR}

- Radiation protection simulation builds physician's awareness to dose levels during interventions provides tools for dose reduction methods and practice dose management as an integral part of the hands-on simulation. It generates real-time dose display; documents scoring with subjective performance metrics; and allows follow-up of the improvement of the trainee [26].

- Artificial intelligence (AI) tools are expected to have an impact on dose management in IR. AI will contribute to image quality improvement, reduction of noise, higher resolution and provide real-time radiation dose estimation and reduction as well as patient-specific and staff dosimetry.

- As the weight of lead aprons often causes discomfort, fatigue, and musculoskeletal problems, different designs of lead aprons are available, some of which aim to reduce the ergonomic hazards and to minimise risks of back injury [27-30].

- Another ongoing development is endovascular robotics. The setup of the remote physician unit eliminates radiation exposure and other occupational hazards, such as spine and musculoskeletal problems. In the PRECISE study, there was a $95.2 \%$ median reduction in radiation exposure to interventionalists, with a $50 \%$ minimum radiation reduction in all cases. The safety and efficacy of using such a system may be maximised by streamlining the workflow and enhancing the setup [31]. 
- In order to safely practice interventional radiology throughout the entire career, IR's have to acquire appropriate training and be periodically updated in radiation protection and dose management.

Funding None.

\section{Declarations}

Conflict of interest All the authors declare that they have no conflict of interest.

Consent for Publication For this type of paper, consent for publication is not required. All the authors have approved the submitted manuscript.

Ethical Approval Not necessary for this paper (review).

Informed Consent For this type of study, consent for publication is not required.

\section{References}

1. ICRP Publication 103. The 2007 Recommendations of the international commission on radiological protection ICRP publication 103. Ann ICRP. 2007;37:1-332.

2. European Council Directive 2013/59/EURATOM on basic safety standards for protection against the dangers arising from exposure to ionising radiation (2014). Off $\mathrm{J}$ Eur Union L 13 57:1-73 Available at https://eur-lex.europa.eu/LexUriServ/LexUriServ. do?uri=OJ:L:2014:013:0001:0073:EN:PDF.

3. ICRP publication 118. ICRP statement on tissue reactions and early and late effects of radiation in normal tissues and organsthreshold doses for tissue reactions in a radiation protection context. Ann ICRP. 2012;41(1-2):1-322.

4. Miller DL, Vano E, Bartal G, et al. Occupational radiation protection in interventional radiology: a joint guideline of the cardiovascular and interventional radiology society of europe and the society of interventional radiology. Cardiovasc Interv Radiol. 2010;33(2):230-9. https://doi.org/10.1007/s00270-009-9756-7.

5. Jaschke W, Bartal G, Martin CJ, Vano E. Unintended and accidental exposures, significant dose events and trigger levels in interventional radiology. Cardiovasc Interv Radiol. 2020;43(8):1114-21. https://doi.org/10.1007/s00270-020-025172.

6. Dauer LT, Miller DL, Schueler B, et al. Occupational radiation protection of pregnant or potentially pregnant workers in IR: a joint guideline of the society of interventional radiology and the cardiovascular and interventional radiological society of europe. J Vasc Interv Radiol. 2015;26(2):171-81. https://doi.org/10.1016/ j.jvir.2014.11.026.

7. ICRP Publication 139. Occupational radiological protection in interventional procedures ICRP publication 139. Ann ICRP. 2018;47(2):1-112.

8. Bartal G, Vano E, Paulo G, Miller DL. Management of patient and staff radiation dose in interventional radiology: current concepts. Cardiovasc Interv Radiol. 2014;37(2):289-98. https:// doi.org/10.1007/s00270-013-0685-0.

9. Livingstone RS, Varghese A. A Simple quality control tool for assessing integrity of lead equivalent aprons. Indian J Radiol Imaging. 2018;28:258-62.
10. Christodoulou EG, Goodsitt MM, Larson SC, et al. Evaluation of the transmitted exposure through lead equivalent aprons used in a radiology department, including the contribution from backscatter. Med Phys. 2003;30(6):1033-8.

11. Orme NM, Rihal CS, Gulati R, et al. Occupational health hazards of working in the interventional laboratory. JACC. 2015;65(8):820-6.

12. Kloeze C, Klompenhouwer EG, Brands PJM, et al. Use of Disposable radiation-absorbing surgical drapes results in significant dose reduction during EVAR procedures. Eur J Vasc Endovasc Surg. 2014;47(3):268-72. https://doi.org/10.1016/j.ejvs.2013.12. 008.

13. Power S, Mirza M, Thakorlal A, et al. Efficacy of a radiation absorbing shield in reducing dose to the interventionalist during peripheral endovascular procedures: a single centre pilot study. Cardiovasc Interv Radiol. 2015;38:573-8. https://doi.org/10. 1007/s00270-014-0997-8.

14. Lambert K, McKeon T. Inspection of lead aprons: criteria for rejection. Oper Radiat Saf, Suppl Health Phys. 2001;80(5):S67-9.

15. Bartal G, Sailer AM, Vano E. Should we keep the lead in the aprons? Tech Vasc Interv Radiol. 2018;21(1):2-6. https://doi.org/ 10.1053/j.tvir.2017.12.002.

16. Uthoff H, Quesada R, Roberts J, et al. Radioprotective lightweight caps in the interventional cardiology setting: a randomised controlled trial (PROTECT). EuroIntervention. 2015;11:53-9.

17. Sans Merce M, Korchi AM, Kobzeva L, et al. The value of protective head cap and glasses in neurointerventional radiology. J NeuroIntervent Surg. 2016;8:736-40. https://doi.org/10.1136/ neurintsurg-2015-011703.

18. Tan BS, Chung JW, Holden A, Gangi A, Binkert K, Morgan R. Checklist for preparing IR service for COVID-19. CIRSEAPSCVIR. Cardiovasc Interv Radiol Society Eur Asia Pac Society Cardiovasc Interv Radiol. 2020;43:1095-6.

19. Ierardi AM, Wood BJ, Gaudino $C$, et al. How to handle a COVID-19 patient in the angiographic suite. Cardiovasc Interv Radiol. 2020;43(6):820-6. https://doi.org/10.1007/s00270-02002476-8.

20. Patel MV, Ahmed O, Hennemeyer C, et al. Interventional radiology is an operational and financial hedge for hospitals during COVID-19. J Vasc Interv Radiol. 2020. https://doi.org/10.1016/j. jvir.2020.07.019.

21. Abadal JM, Nieto JG, Zarraga FL, et al. Future scenarios and opportunities for interventional radiology in the post COVID-19 era. Diagn Interv Radiol. 2020. https://doi.org/10.5152/dir.2020. 20494.

22. Durán A, Hian SK, Miller DL, Le Heron J, Padovani R, Vano E. Recommendations for occupational radiation protection in interventional cardiology. Catheter Cardiovasc Interv. 2013;82(1):29-42. https://doi.org/10.1002/ccd.24694.

23. Madder RD, VanOosterhout S, Mulder A, et al. Patient body mass index and physician radiation dose during coronary angiography: is the obesity epidemic impacting the occupational risk of physicians in the catheterization laboratory? Circ Cardiovasc Interv. 2019;12:e06823.

24. Vano E. Radiation exposure to cardiologists: how it could be reduced. Heart. 2003;89(10):1123-4. https://doi.org/10.1136/ heart.89.10.1123.

25. Vano E, Sanchez RM, Fernandez JM. Strategies to optimise occupational radiation protection in interventional cardiology using simultaneous registration of patient and staff doses. J Radiol Prot. 2018;38(3):1077-88. https://doi.org/10.1088/13616498/aad429.

26. Sánchez RM, Vano E, Fernández JM, et al. Occupational eye lens doses in interventional cardiology. A multicentric study J Radiol Prot. 2016;36(1):133-43. https://doi.org/10.1088/0952-4746/36/ $1 / 133$. 
27. Vano E, Sanchez RM, Fernandez JM. Estimation of staff lens doses during interventional procedures. comparing cardiology, neuroradiology and interventional radiology. Radiat Prot Dosim. 2015;165(1-4):279-83. https://doi.org/10.1093/rpd/ncv049.

28. See KWM, Chui KH, Chan WH, et al. Evidence for endovascular simulation training: a systematic review. Eur J Vasc Endovasc Surg. 2016;51:441-51.

29. Dixon RG, Khiatani V, Statler JD, et al. Society of interventional radiology: occupational back and neck pain and the interventional radiologist. J Vasc Interv Radiol. 2017;28(2):195-9. https://doi. org/10.1016/j.jvir.2016.10.017.
30. Bartal G, Roguin A, Paulo G. Call for implementing a radiation protection culture in fluoroscopically guided interventional procedures. AJR Am J Roentgenol. 2016;206(5):1110-1. https://doi. org/10.2214/AJR.15.15986.

31. Weisz G, Metzger DC, Caputo RP, et al. Safety and feasibility of robotic percutaneous coronary intervention: PRECISE (Percutaneous Robotically-Enhanced Coronary Intervention) study. J Am Coll Cardiol. 2013;61(15):1596-600.

Publisher's Note Springer Nature remains neutral with regard to jurisdictional claims in published maps and institutional affiliations. 